\title{
Drug Use and Sex Work Among At-risk Women: A Qualitative Study of Initial Factors
}

\author{
Payam Roshanfekr ${ }^{1}$; Roya Noori ${ }^{2, *}$; Masoumeh Dejman ${ }^{1}$; Zahra Fathi Geshnigani ${ }^{3}$; Hassan \\ Rafiey $^{4}$
}

${ }^{1}$ Social Determinant of Health Research Center, University of Social Welfare and Rehabilitation Sciences, Tehran, IR Iran

${ }^{2}$ Substance Abuse and Dependence Research Center, University of Social Welfare and Rehabilitation Sciences, Tehran, IR Iran

${ }^{3}$ Family Health Association of Iran, Tehran, IR Iran

${ }^{4}$ Department of Social Welfare, University of Social Welfare and Rehabilitation Sciences, Tehran, IR Iran

${ }^{*}$ Corresponding author: Roya Noori, Substance Abuse and Dependence Research Center, University of Social Welfare and Rehabilitation Sciences, Tehran, IR Iran. Tel: +98-2122180095, Fax:+98-2122180095, E-mail: roya_noori2020@yahoo.com

Received: April 8, 2014; Revised: October 6, 2014; Accepted: February 14, 2015

Background: In recent years, there has been an increasing interest in performing research on drug use and sex work among at-risk women. Although there is a well-documented literature of the initial reasons associated with drug use and sex work among women, there is, however, a paucity of information in this area in Iran.

Objectives: This study aimed to explore the initial reasons associated with drug use and sex work in a group of female treatment seekers, who presented health-related risk behaviors, in Tehran, Iran.

Patients and Methods: This qualitative study enrolled a total of 65 at-risk women, from five women-specific drug clinics, who participated in the study in 2011. Individual in-depth interviews were conducted. Focus group interviews were conducted with 10 key informants. All interviews were audio-taped and thematically written. The recorded data were analyzed using ATLASti qualitative research software version 10.

Results: The median age of the sample was 34 years. In addition, $44.6 \%$ of subjects were opiate users, and $55.4 \%$ were users of opiates and methamphetamine. Sex work was the main source of income for almost half of the sample. The most frequently reported reasons, associated with initial drug use, were extrinsic motivations, including the drug-using family, friends or social networks. Intrinsic motivations, including curiosity and individual willingness to use drugs, were other initial reasons. The most frequently reported reasons, associated with initial sex work, included the need to purchase drugs and financial problems.

Conclusions: The study findings demonstrated a number of reasons associated with initial drug use and sex work. The role of sex work in providing drugs necessitates education and prevention. Special treatment programs should be implemented to prevent sex work among at-risk women in Iran.

Keywords: Qualitative Research; Treatment; Women

\section{Background}

In recent years, there has been an increasing interest in the research of drug use and sex work among at-risk women (1-4). Studies show that drug use is a common behavior among at-risk women who practice sex work or have used injectable substances $(5,6)$. A recent study of 872 Iranian at-risk women showed that sex work was a common way to procure drugs among this group of individuals (2). A study on 51 female drug users found that the majority of women were daily heroin users, and many reported drug dependence. Among women, sex work was a common way to purchase drugs (7). Drug use among at-risk women, such as drug injectors and sex workers, has not been well documented because of the stigma and discrimination in Iran (2). It is critical to understand the reasons that at-risk women, such as sex workers and drug injectors, report for initial drug use, so that an effective strategy could be proactively formulated to address treatment needs, based on initial factors associated with this problem.

\section{Objectives}

The current preliminary study aimed to explore the initial factors associated with drug use and sex work among a group of woman treatment seekers in Tehran, the capital city of Iran.

\section{Materials and Methods}

\subsection{Study Design and Centers}

The study design was qualitative because of the dearth

Copyright (C) 2015, Mazandaran University of Medical Sciences. This is an open-access article distributed under the terms of the Creative Commons Attribution-NonCommercial 4.0 International License (http://creativecommons.org/licenses/by-nc/4.0/) which permits copy and redistribute the material just in noncommercial usages, provided the original work is properly cited. 
of studies of initial factors associated with drug use among Iranian at-risk women. We selected qualitative methodology because it can develop research by identifying additional relevant variables, generating new hypotheses $(8,9)$. The study was part of a larger study of high-risk behaviors among women drug users, at five women-specific drug treatment centers, in the south of Tehran, from June to November 2011. The parent study included HIV service needs among at-risk women who were engaged in drug injection and/or sex work. The parent study was a joint research project between the United Nations Office on Drugs and Crime (UNODC) and Substance Abuse and the Dependence Research Center, University of Social Welfare and Rehabilitation Sciences, Tehran.

\subsection{Inclusion and Exclusion Criteria}

Inclusion criteria for participants were: 1 ) age $>18$ years; 2) drug dependence, based on the Diagnostic and Statistical Manual of Mental Disorders, Fourth Edition, Text Revision, 1994, criteria; 3 ) being in a drug treatment for at least 2 months; 4) being at-risk, and 5) signing the consent form for study participation. At-risk was defined as practicing high-risk behaviors, including sex work and/ or drug injection. Reporting severe drug withdrawal and/ or intoxication were the exclusion criteria. Screening of the patients was conducted by a well-trained psychiatrist, who was part of research team.

\subsection{In-depth Individual Interviews With Women}

A total of 65 at-risk women, who were in drug treatment for at least 2 months, were recruited by convenience sampling. Although the manager of each center referred eligible candidates to interviewers, however, screening, sample recruitment and the interviewing procedure were conducted by interviewers. Based on the study guideline, a semi-structured interview was developed to explore demographics, details of drug use and the selfperceived reasons, associated with initial drug use and sex work. Face-to-face and in-depth interviews were conducted by the lead author. Interviews were individual and included open-ended questions. Each interview focused on the events and issues surrounding the initial drug use and sex work. Each interview took 60 - 90 minutes. Interviews were transcribed verbatim by a research assistant and reviewed by the lead author, for accuracy. The interview period was limited to the months between June and November, because qualitative analysis of the interviews showed that we reached data saturation (8) and no new themes were emerging from continued interviews. Interviews were conducted in women's drug treatment centers or other locations in their neighborhood, in order to enhance the comfort and convenience of women.

\subsection{Focus Group Interviews With Key Informants}

Ten health providers were interviewed as key infor- mants. The key informants were women's physicians, psychologists, nurses, and social workers. Overall, three focus group interviews were conducted, which took 40 - 50 minutes. Each group included three to four key informants. The purposes of the focus groups for this study were: 1) to obtain information from health providers and 2) to compare the key issues in the key informant interviews and interviews with women. The focus group interviews provided a facilitative, non-threatening group environment, in which we explored the perceptions and personal experiences regarding initial drug use and sex work. Detailed narrative data were collected. Groups discussed issues related to initial factors, associated with drug use and sex work. All focus group interviews were conducted by three well-trained ethnographers, with at least 8 years of drug-related research qualifications and professional training in qualitative methodology. In addition, all interviews were audio-taped with prior permission from women and key informants.

\subsection{Ethical Considerations}

Ethic approval for the study was received from the Human Research Ethics Committees of the University of Social Welfare and Rehabilitation Sciences and UNODC in Tehran. The informed consent form was signed by each participant. Participation was confidential and anonymous. Women were informed that disagreement with study participation would not impact their drug treatment or their relation with their treatment teams. All women were reimbursed with retail vouchers for study participation. After each interview, women got incentive as gifted card equal to 100,000 Rials due to their time for the interview.

\subsection{Data Analysis}

Our data analysis focused on the initial factors associated with drug use and sex work. Interview transcripts were imported into ATLASti qualitative analysis software version 10 (Scientific Software Development GmbH., Berlin, Germany) to assist with data management and coding. We used a coding framework to thematically analyze the data (10). Thematic analysis involved systematically identifying and coding themes, based on those covered in the interviews. Following this initial coding of themes, sub-themes were inductively identified for each theme. Patterns and contradictions within and between themes and sub-themes were elucidated, using an iterative process. Content and theme analyses were extensively conducted (9). The main categories and subcategories related to drug use and sex work gradually emerged from data analysis. Data analysis was monitored independently by two team members, who met regularly with the larger team to discuss emerging themes and revise the coding framework. Once the final categories were established, the lead author reviewed the data analysis to enhance their validity. 
Table 1. Demographic Characteristics of At-risk Women in Drug Treatment Clinics in Tehran $(\mathrm{n}=65)^{\mathrm{a}}$

\begin{tabular}{|c|c|}
\hline Characteristics & Value \\
\hline Age range, y & $18-65$ \\
\hline Median age, y & 34 \\
\hline \multicolumn{2}{|l|}{ Schooling, y } \\
\hline$<12$ & $53(81.5)$ \\
\hline 12 & $8(12.3)$ \\
\hline$>12$ & $4(6.2)$ \\
\hline \multicolumn{2}{|l|}{ Marital status } \\
\hline Divorced & $26(40.0)$ \\
\hline Widowed & $14(21.0)$ \\
\hline Married & $13(20.0)$ \\
\hline Single & $10(15.0)$ \\
\hline Separated & $2(4.0)$ \\
\hline \multicolumn{2}{|l|}{ Living conditions } \\
\hline With family & $35(53.8)$ \\
\hline Homeless & $30(46.2)$ \\
\hline $\begin{array}{l}\text { Mean duration of drug } \\
\text { dependence, } y\end{array}$ & $10 \pm 8$ \\
\hline \multicolumn{2}{|l|}{ Main type of drug use } \\
\hline Opiate & $29(44.6)$ \\
\hline $\begin{array}{l}\text { Opiate and methamphet- } \\
\text { amine }\end{array}$ & $36(55.4)$ \\
\hline \multicolumn{2}{|l|}{ Main routes of drug use } \\
\hline Injection & $35(53.8)$ \\
\hline Smoking & $30(46.2)$ \\
\hline \multicolumn{2}{|l|}{ Main sources of income } \\
\hline Sex work & $32(49.2)$ \\
\hline Family & $16(28.6)$ \\
\hline Theft/beggary & $9(13.8)$ \\
\hline Drug dealing & $5(7.7)$ \\
\hline Employment & $3(4.6)$ \\
\hline
\end{tabular}

${ }^{\mathrm{a}}$ Data are presented as No. (\%) or Mean $\pm \mathrm{SD}$.

\section{Results}

\subsection{Demographic Characteristics}

The median age of participants was 30 - 40 years and almost half were divorced. Most participants had less than 12 years of education. Half of the cohort was opiate users (e.g., opium or heroin) and the other half were users of opiates plus methamphetamine. More than 50\% were drug injectors (Table 1 ).

\subsection{Initial Drug Use}

Data analysis showed the roles of two main categories in
Table 2. Motivations Associated With Initial Drug Use and Sex Work $(\mathrm{n}=65)^{\mathrm{a}}$

\begin{tabular}{|c|c|}
\hline Variable & Value \\
\hline \multicolumn{2}{|l|}{ Extrinsic motivations } \\
\hline Drug-using family members/relatives & $46(71.0)$ \\
\hline Drug-using friends or social networks & $35(53.8)$ \\
\hline \multicolumn{2}{|l|}{ Intrinsic motivations } \\
\hline Curiosity & $31(47.7)$ \\
\hline Individual willingness to use drugs & $20(31.0)$ \\
\hline \multicolumn{2}{|l|}{ Initial reasons for sex work } \\
\hline A need to purchase drugs & $33(51.0)$ \\
\hline Financial problems & $32(49.0)$ \\
\hline
\end{tabular}

the initial drug use, including extrinsic and intrinsic motivations (Table 2). The categories below emerged from themes and sub-themes elicited from the interviews.

\subsubsection{Extrinsic Motivations}

Extrinsic motivations included those factors that externally motivated women to initiate drug use. Extrinsic motivations were available in the surroundings of women. Extrinsic motivations included drug-using family members/relatives and drug-using friends or social networks.

\subsubsection{Drug-Using Family Members/Relatives}

The majority of women $(n=46)$ reported that they initiated drug use in the family or among their relatives. A drugusing spouse, mother, brother, father or an aunt played a significant role at initiation. Several of them $(n=21)$ reported that they were either encouraged or forced to initiate drug use. Forcing them to use the drugs was reported as a strategy to prevent them from complaining of drug use in the family. In addition, the majority of women $(n=39)$, reported someone in the family, usually a man, provided drugs at initiation. A 30-year-old jobless woman, who lived with her family, told the following: “...My husband was an addict. He used to sell opium. When we had a struggle, he told me.... I would make you an addict. I tried not to be an addict, but he persuaded me. At the beginning, I took oral opium and then I started opium smoking...".

A key informant, who was a physician, reported the following: “...Several women start drug use in the family. Most of them are encouraged or forced by their husbands to initiate drug use. It is a way to keep them silent against drug use in the family. We need more drug education...”.

\subsubsection{Drug-Using Friends or Social Networks}

A number of women $(n=35)$ reported that drug-using friends or social networks, such as men friends or neighbors, contributed to initial drug use in their cases. Several of them $(n=23)$ reported that they initiated drug use with boyfriends or men partners, in recreational situations, 
such as parties. Several of these participants reported initial sex with their drug-using men friends. A 29-year-old jobless woman, who had two children, declared as follows: “...I loved an opium-using guy and started opium use and then sex with him. We used to smoke opium and enjoyed together. It was just for fun in the beginning and then I became an addict...".

A key informant who provided psychological services for women related the following: “....Number of women initiate drug use because of drug-using friends or social networks that encourage drug use and provide drugs for them, at initiation...It is very important that we provide drug education for women...”.

\subsubsection{Intrinsic Motivations}

Intrinsic motivations included those motivations that internally motivated women to initiate drug use. Intrinsic motivations included curiosity and individual willingness to use drugs.

\subsubsection{Curiosity}

Number of women reported $(n=31)$ that they initiated drug use because of curiosity. They reported that they were experience seekers. A 27-year-old sex worker, who was homeless, declared the following: “....No one takes the blame for drug use. I was curious to use drugs and started drug use... I wished to have the experience...."

A key informant who provided social work services for the women declared that: “... Several women start drug use because they are curious to take a drug. They do not have much information about drug use. They do not care about drug addiction. We need to provide drug education for them....".

\subsubsection{Individual Willingness to Use Drugs}

Several women reported $(n=20)$ that no one played a role at drug initiation, and they initiated drug use because of one's individual willingness to use drugs. A 26-year-old jobless women, who lived with her family, told as follows: "... I had a woman friend. We drank alcohol together in her home. She had two kids. Two years ago, we smoked opium... I wanted to do so...".

A key informant who provided social work services told as follows: “... A number of women start drug use because they are willing to take a drug. They do not think much of the long-term side effects of drug use, at initiation. We need to provide drug education for them. It is really necessary...."

\subsection{Initial Reasons for Sex Work}

\subsubsection{Sex Work to Purchase Drugs}

Most women $(n=33)$ reported that they initiated sex work to purchase drugs. They reported that they initiated sex work either to provide drugs for themselves, or a man in the family, such as their spouses, brothers or fathers. Several of them $(n=18)$ reported that they were forced to initiate sex work to provide drugs for their spouses or the men in their families.

A 30-year-old sex worker who was homeless told as follows: “... Prostitution is related to a woman's drug use; because this (body) is the only thing she owns and can sell to her buyer. Therefore, you can buy drugs, as long as there is this body...".

A 35-year-old homeless sex worker told as follow: “...My drug-using husband borrowed money to pay his debts and then forced me to sleep with someone for an hour to get money...then, I continued sex work to buy drugs for myself...”.

A key informant who was a physician declared that: “... Several of these women start sex work to get money for buying drugs. In most situations, they have drug-addicted husbands or men in their families. They force the women to have sex with others for money...Most of them start sex for drugs...".

\subsubsection{Financial Problems}

Financial problems $(n=32)$ were frequently reported by several women, as a main factor associated with initial sex work. They frequently reported that they had no jobs, and they had to start sex work to provide money for themselves or their families.

A 36-year-old sex worker told as follows: “... When I had no place to smoke drugs, I had to go to strangers' homes, and there is always sex there. If drug-addicted women have no jobs, they will go for prostitution...".

A key informant, who provided nursing services for women, told as follows: “... Financial problems play an important role for our women to start sex work. We should provide jobs for them; otherwise they will sell their bodies for money...".

\section{Discussion}

The current study is one of the first studies that preliminarily showed the initial factors associated with drug use and sex work among a group of at-risk women, who were seeking drug treatment in Tehran. A number of extrinsic and intrinsic motivations were associated with initial drug use and sex work among the studied cases. Most of these women frequently reported that they initiated drug use because of drug-using family members and relatives. The availability of drugs among their families and relatives followed by encouraging or forcing them to use drugs, were important triggers at initiation. Their drug-using family members or relatives were likely to realize that a non-drug-using family member was a threat against continued drug use. Therefore, they encouraged or forced several of the women to initiate drug use. Studies show that women are more likely to have relatives who have drug use issues (11). Women are more likely than men to have a spouse who uses drugs (12). Drug-using friends or social networks were frequently reported by several of our women, as initial factors associated with 
drug use. Drug-using friends, especially men friends, and social networks, such as neighbors, were likely to consider offering drugs to the study women as a strategy to show intimacy or close friendship. Drug availability facilitated by social networks, such as men friends, has been frequently cited as an initial factors associated with drug use among women (11-13). Several women reported that they initiated drug use because of their intrinsic motivations. They reported that they were curious about the effects of drug use. They were likely to consider drug use as a recreational activity or as a strategy to self-medicate mental distress. Intrinsic motivations still deserve further research and necessitate implementing drug education and prevention programs. In addition, several women reported that they initiated drug use because of an individual willingness. These women should be informed about the side effects of drug use before making a decision to start drugs, by recognizing their high risk for such a dependence behavior. Several studies in the US showed that women initiated drug use because of an individual willingness to use drugs, such as self-medication (12). The study results confirmed the reasons associated with initial drug use and sex work. Providing money to purchase drugs was the most frequently reported reason for initial sex work among several of the women in our study. There were participants who reported that they were forced by a man in the family to initiate sex with others to provide money for drugs. Drug education about the harms associated with sex work including HIV and hepatitis $\mathrm{C}$ virus (HCV) should be provided for these women and their families. Providing counseling and training services to find jobs is suggested. Literature has shown a strong relationship between sex work and drug use in other countries, such as the US (14-16). Cusick et al. (17) identified vulnerability and involving in sex work among 125 drug-using women. They found that most sex workers started sex to provide money for drugs. Several women reported that they were unemployed and required money for themselves or their families. Lack of vocational training and counseling were likely to be important reasons associated with initial sex work among those women. They were likely to have no information about job opportunities in the community. Studies show that drug-dependent women, under specialized treatment, require counseling and training to find jobs (18). To sum up, drug use may contribute to initial sex work among women and vice versa. Women sex workers, who are drug-dependent, have special treatment needs. In addition to drug treatment, they may need vocational training, financial support, family therapy, safe sex education, safe injection and free HIV/HCV testing, counseling and treatment. Women-only programs have been found to provide a greater number of the ancillary services needed by women (19), which may facilitate treatment enrollment and retention (20). In addition to women-only participants, women staff members who can serve as role models are also seen as providing a positive impact on the treatment environment (21). Special drug treatment and supportive services should be provided for at-risk women drug users in Iran, to prevent sex work. In addition, staff training and education should be provided in Iran when at-risk women drug users, especially sex workers, enter drug treatment.

The study also had several limitations. First, the study design was cross-sectional. Second, the study sample was limited to a group of at-risk women at five women centers in Tehran who were engaged in drug injection or sex work. As a result, the study results may not be generalizable to other groups of women drug users or other parts of Iran. Third, because of the paucity of research, our methodology was limited to content analysis techniques and qualitative design. Further studies, with a more representative number of women, are suggested. In addition, a combination of qualitative and quantitative analyses may provide more information on this issue.

\section{Acknowledgements}

The authors would like to thank the study participants for sharing their experiences.

\section{Authors' Contributions}

Payam Roshanfekr and Hassan Rafiey designed the study. Payam Roshanfekr, Hassan Rafiey, and Masoumeh Dejman conducted the interviews. Roya Noori analyzed the data. Zahra Fathi Geshnigani contributed in writing the manuscript. All authors contributed to the critical revision of the manuscript and approved the final version.

\section{Declaration of Interest}

None Declared.

\section{References}

1. Vanwesenbeeck I. Another decade of social scientific work on sex work: a review of research 1990-2000. Annu Rev Sex Res. 2001;12:242-89.

2. Sajadi L, Mirzazadeh A, Navadeh S, Osooli M, Khajehkazemi R, Gouya MM, et al. HIV prevalence and related risk behaviours among female sex workers in Iran: results of the national biobehavioural survey, 2010. Sex Transm Infect. 2013;89 Suppl 3:iii37-40.

3. Nasirian M, Doroudi F, Gooya MM, Sedaghat A, Haghdoost AA. Modeling of human immunodeficiency virus modes of transmission in iran.J Res Health Sci. 2012;12(2):81-7.

4. Haghdoost AA, Mostafavi E, Mirzazadeh A, Navadeh S, Feizzadeh A, Fahimfar N. Modelling of HIV/AIDS in Iran up to 2014. J AIDS HIV Res. 2011;3(12).

5. Alegria M, Vera M, Freeman DHJ, Robles R, Santos MC, Rivera CL. HIV infection, risk behaviors, and depressive symptoms among Puerto Rican sex workers. Am J Public Health. 1994;84(12):2000-2.

6. Maher L. Sexed work: Gender, race and resistance in a Brooklyn drug market.Oxford UK: Oxford University Press; 1997.

7. Gossop M, Powis B, Griffiths P, Strang J. Female prostitutes in south London: use of heroin, cocaine and alcohol, and their relationship to health risk behaviours. AIDS Care. 1995;7(3):253-60.

8. Kuzel AJ. Sampling in qualitative inquiry. In: Crabtree BF, Miller WL editors. Doing qualitative research.. Thousand Oaks: SAGE Publications; 1999. 
9. Strauss A, Corbin JM. Basics of qualitative research: Grounded theory procedures and techniques.Thousand Oaks: SAGE Publications; 1990.

10. Patton MQ. Qualitative research \& evaluation methods.Thousand Oaks: SAGE Publications; 2002.

11. Chermack ST, Stoltenberg SF, Fuller BE, Blow FC. Gender differences in the development of substance-related problems: the impact of family history of alcoholism, family history of violence and childhood conduct problems. J Stud Alcohol. 2000;61(6):845-52.

12. Langan NP, Pelissier BM. Gender differences among prisoners in drug treatment.J Subst Abuse. 2001;13(3):291-301.

13. Higgs P, Owada K, Hellard M, Power R, Maher L. Gender, culture and harm: an exploratory study of female heroin users of Vietnamese ethnicity. Cult Health Sex. 2008;10(7):681-96.

14. Farley M, Kelly V. Prostitution a critical review of the medical and social sciences literature. Women Crim Justice. 2008;11(4):29-64.

15. Hendershot CS, George WH. Alcohol and sexuality research in the AIDS era: trends in publication activity, target populations and research design. AIDS Behav. 2007;11(2):217-26.

16. Lau JT, Tsui HY, Lam LT, Lau M. Cross-boundary substance uses among Hong Kong Chinese young adults. J Urban Health. 2007;84(5):704-21.

17. Cusick L, Martin A, May T. Vulnerability and involvement in drug use and sex work.: Home Office London; 2003.

18. Gregoire TK, Snively CA. The relationship of social support and economic self-sufficiency to substance abuse outcomes in a longterm recovery program for women.J Drug Educ. 2001;31(3):221-37.

19. Grella CE, Polinsky ML, Hser YI, Perry SM. Characteristics of women-only and mixed-gender drug abuse treatment programs. $J$ Subst Abuse Treat. 1999;17(1-2):37-44.

20. Logan TK, Walker R, Cole J, Leukefeld C. Victimization and substance abuse among women: Contributing factors, interventions, and implications. Rev Gen Psychol. 2002;6(4):325-97.

21. Lockwood D, McCorkel J, Inciardi JA. Developing comprehensive prison-based therapeutic community treatment for women. Drugs and Society. 1998;13(1-2):193-212. 